\section{Myopericarditis Revealing Giant Cell Arteritis in the Elderly}

\section{To the Editor:}

We read with great interest the report by Pugnet, et al describing the case of acute myocarditis revealing giant cell arteritis (GCA) in an elderly patient ${ }^{1}$. We describe a new case of myopericarditis heralding GCA.

A 67-year-old man was admitted to the cardiology intensive care unit for acute precordial chest pain radiating in his jaw, associated with dyspnea. He recently experienced deterioration of his general health. His history included psoriasis and dyslipidemia treated with atorvastatin. No other cardiovascular risk factor was noted. Examination did not reveal any sign of cardiac insufficiency and was normal except for diffuse psoriasis lesions. Biological evaluations showed normal levels of cardiac troponin $\mathrm{I}$ but detected a high inflammatory process with fibrinogen at $8 \mathrm{~g} / \mathrm{l}$ (normal < 4), C-reactive protein at $285 \mathrm{mg} / \mathrm{l}($ normal $<10)$, and white blood cell count at $11.3 \times 10^{9} / 1$. Electrocardiogram showed negative $\mathrm{T}$ waves in the lateral cardiac area. Echocardiography revealed a moderate pericardial effusion and left ventricle hypertrophy with normal systolic and diastolic left ventricular function. Due to normal biomarkers of cardiac injury and results of echocardiography, no coronarography was performed. Indeed, the diagnosis of myopericarditis was suspected and then confirmed by cardiac magnetic resonance imaging (MRI), which showed delayed gadolinium enhancement on the epicardial side of the lateral left ventricular wall, typical of acute myocarditis, and a moderate pericardial effusion (Figures 1A, 2A). Etiological research for myopericarditis, including viral, bacterial, and parasitic infections, and investigation for autoimmune diseases remained negative. A thoraco-abdominal computed tomography scan detected a thickening of the wall of the whole aorta. Positron emission tomography (PET) with 18 FDG showed a hypermetabolism of the thoracic and abdominal aorta extending to the subclavian arteries. Considered together, the large vessel inflammation, myopericarditis, the alterations of general health, and the biological inflammatory process occurring in a patient older than age 50 years strongly suggested the diagnosis of GCA, even in the absence of temporal signs. Finally, histopathological analysis of a temporal artery biopsy gave results typical of GCA. The clinical outcome was successful under treatment with steroids, with regression of biological inflammation, healing of the myopericarditis (Figures 1B, 2B), and decrease in metabolic activity of the aorta wall on PET scan. With 2 years of followup and under a very low dose of steroids, the patient remained in good health with complete normalization of cardiac MRI findings.

GCA preferentially affects the external carotid artery and its branches, and more specifically the superficial temporal artery, which explains the usual clinical signs of the disease. Currently, cardiac manifestations are rarely described in the literature, as only 3 cases of GCA-related myopericarditis are reported ${ }^{1,2}$. Pericarditis without myocarditis has also been reported, as inaugural manifestation of $\mathrm{GCA}^{3,4}$. Steroids were effective in almost all these cases. In contrast to the case reported by Pugnet, et $\mathrm{al}^{1}$, temporal signs of GCA were missing in our case and those reported by Teixera, et $a l^{2}$. However, in the review by Bablekos, et $a l^{4}$ pericardial

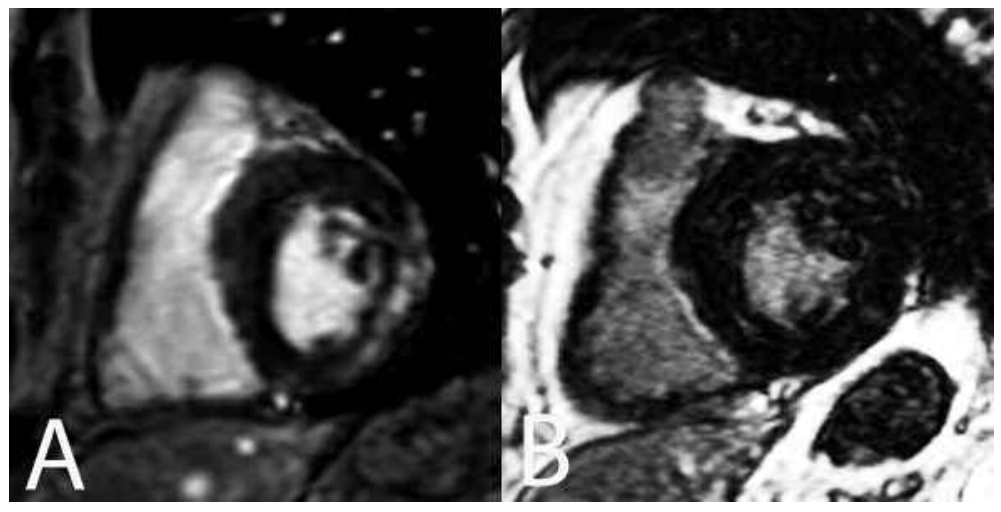

Figure 1. Delayed enhanced cardiac magnetic resonance images in short axis view $5 \mathrm{~min}$ after injection of gadolinium $0.2 \mathrm{mmol} / \mathrm{kg}$ during the first week after the onset of pain (A) and 6 months later (B). In (A), myocardial enhancement is located in the epicardial border of the lateral wall of the left ventricle; in (B) the enhancement has disappeared.

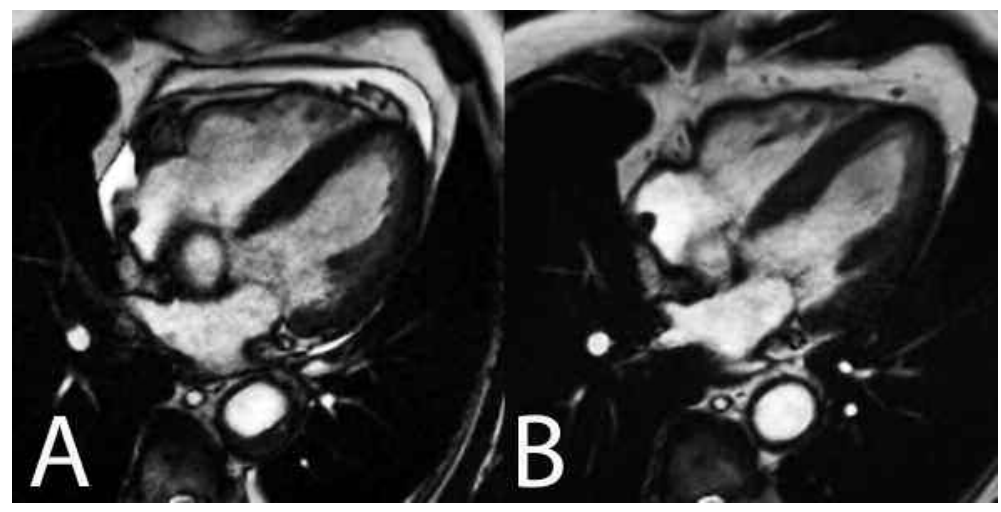

Figure 2. Images in end-diastolic phase; during the first week after the onset of pain, pericardial effusion is clearly visible during the diagnosis (A) and disappears completely 6 months later (B). 
involvement in GCA was associated with classical temporal signs of the disease in two-thirds of the cases.

Currently cardiac MRI plays a key role in the diagnosis and management of myocarditis ${ }^{5,6}$. In the study by Mahrholdt, et al $^{7}$ a good correlation was observed between the contrast enhancement on MRI images and the MRI-driven myocardial biopsies showing active inflammation, confirming that cardiac MRI is a valuable tool for evaluation and monitoring of myocarditis. Therefore, as cardiac MRI may provide an alternative method for diagnosis of myocarditis ${ }^{6}$, the standard Dallas pathological criteria for the definition for myocarditis are currently discussed due to the low sensitivity, lack of prognostic value, and the risks of biopsy ${ }^{5}$.

Physicians should consider pericarditis and myocarditis as possible manifestations of GCA in subjects over 50 years old, even in the absence of typical manifestations of temporal arteritis ${ }^{4,8}$. Further large studies are required to evaluate the frequency of pericarditis and/or myocarditis associated with GCA. We suggest that both electrocardiogram and echocardiography should be systematically performed when presentation includes GCA.

AURÉLIE DAUMAS, MD; PASCAL ROSSI, MD, PhD, Service de Médecine Interne, Hôpital Nord, Assistance Publique-Hôpitaux de Marseille; ALEXIS JACQUIER, MD, PhD, Service d'Imagerie Médicale, Hôpital de la Timone, Assistance Publique-Hôpitaux de Marseille; BRIGITTE GRANEL, MD, Service de Médecine Interne, Hôpital Nord, Assistance Publique-Hôpitaux de Marseille, Marseille, France. Address correspondence to Dr. B. Granel, Service de Médecine Interne, Hôpital Nord, Chemin des Bourrely, 13915 Marseille cedex 15, France.

E-mail: bgranel@ap-hm.fr

\section{REFERENCES}

1. Pugnet G, Pathak A, Dumonteil N, Arlet P, Sailler L. Giant cell arteritis as a cause of acute myocarditis in the elderly [letter]. J Rheumatol 2011;38:2497-8.

2. Teixera A, Capitaine E, Congy F, Herson S, Cherin P. Atteinte myopéricardique au cours de la maladie de Horton. Rev Med Interne 2003;24:189-94.

3. Guindon A, Rossi P, Bagneres D, Aissi K, Demoux A-L, Bonin-Guillaume S, et al. La péricardite: une manifestation de la maladie de Horton. Rev Med Interne 2007;28:326-31.

4. Bablekos GD, Michaelides SA, Karachalios GN, Nicolaou IN, Batistatou AK, Charalabopoulos KA. Pericardial involvement as an atypical manifestation of giant cell arteritis: Report of a clinical case and literature review. Am J Med Sci 2006;332:198-204.

5. Cooper LT Jr. Myocarditis. N Engl J Med 2009;360:1526-38.

6. Friedrich MG, Sechtem U, Schulz-Menger J, Holmvang G, Alakija P, Cooper LT, et al; International Consensus Group on Cardiovascular Magnetic Resonance in Myocarditis. Cardiovascular magnetic resonance in myocarditis: A JACC White Paper. J Am Coll Cardiol 2009;53:1475-87.

7. Mahrholdt H, Goedecke C, Wagner A, Meinhardt G, Athanasiadis A, Vogelsberg H, et al. Cardiovascular magnetic resonance assessment of human myocarditis: A comparison to histology and molecular pathology. Circulation 2004;109:1250-8.

8. Granel B, Serratrice J, Rey J, Pache X, Swiader L, Habib G. La péricardite idiopathique chronique ou récidivante est-elle une maladie inflammatoire autonome? Rev Med Interne 2001; 22:1204-12.

J Rheumatol 2012:39;3; doi:10.3899/jrheum.110934 